\title{
PERFILES
}

\section{C.L.R. James (1901-1989) Más allá de las fronteras}

\author{
Paula Varela y Gastón Gutiérrez \\ UBA-Conicet • UBA \\ paula.varela.ips@gmail.com・gaston.ips@gmail.com
}

Un perfil de Cyril Lionel Robert James para el público lector en castellano tiene la obvia dificultad de que la mayor parte de sus obras no están traducidas. El reconocimiento de Los jacobinos negros (todas las referencias a esta obra remiten a James, 2003) como libro pionero de los estudios de la revolución en el subcontinente, contrasta con lo poco conocido que son el resto de sus textos en nuestro medio. Paradójicamente, a pesar de sus aportes para pensar más allá del eurocentrismo, James continúa siendo una figura circunscripta al medio anglófono. Es alli donde pueden encontrarse testimonios elogiosos, como el de Edward Said que postuló que James ejemplifica cabalmente la figura del artista como revolucionario (Said, 1989); o críticos, como el de Robin Blackburn, que lo calificó como exponente de un desarticulado "anarcobolchevismo" (Richardson, 1993).

Más allá de las valoraciones, hacia fines de los 80 y principio de los 90, James comenzó a ser referente de diferentes tipos de apropiaciones tanto por parte de la academia anglosajona, como por un heterogéneo archipiélago de pensamientos críticos que produjo la aparición de "many James". Hay un "James escritor" pensado como parte del florecimiento intelectual de las West Indies; hay un "James historiador", pionero de la historiografia "desde abajo"; hay un "James posmarxista", que luego de su paso por el trotskismo, se habria adelantado en proponer un marxismo posleninista que enfatizara la autoactividad de las masas en contra de los partidos y las organizaciones; un "James culturalista" que, con sus trabajos sobre la cuestión negra y la vida cotidiana de los sectores más postergados de la sociedad capitalista, habría permitido una mejor comprensión del lugar de la cultura (cuyo obvio heredero es el también caribeño Stuart Hall); y por último, habria un "James poscolonial" que de activo promotor del movimiento panafricano en las luchas revolucionarias por la descolonización habría dejado un legado 
ensamblable con el "giro decolonialista". En un sentido C.L.R. James fue un poco todas esas cosas, de ahí que un rasgo del que dan cuenta la mayoría de sus biografias y de los estudios sobre sus escritos, es del carácter iconoclasta del intelectual negro antillano, marcado por su particular acento libertario del marxismo en el contexto de la izquierda del siglo XX. ${ }^{1}$ Ante este panorama, este perfil trazará algunos de los principales acontecimientos de su biografia politica e intelectual, y remarcará aquellos núcleos característicos de la obra de C.L.R. James. ${ }^{2}$

\section{"Una vida ligada a la revolución" (1901-1989)}

La larga biografia de James comienza en 1901 en el pequeño pueblo de Tunapuna, a 8 millas de Port Spain, la capital de la isla de Trinidad. Su madre, una ávida lectora de literatura inglesa, le inspiró el amor por la lectura y la vocación literaria. Su padre, maestro y reconocido director de escuela de la isla (amigo personal del padre de otro joven llamado a cumplir un rol en el movimiento comunista primero, y panafricano después, George Padmore), era pedagogo y, según James, "un muy buen maestro" que le inculcó la pasión por el conocimiento de los clásicos. Ambos, obviamente, anglicanos. El joven James, que asistió a una secundaria pública inglesa de prestigio, la Queen's Royal College, desarrolló dos pasiones. Una, la literatura y el deseo de volverse escritor. La otra, el cricket, viejo deporte inglés que se había establecido en la isla como un deporte popular. Como explicara él en Beyond a Boundary, fundamental para la personalidad de los jóvenes triniteños, alienados del resto de la riqueza cultural del imperio inglés, el cricket aparecía como un espacio de apropiación y formación cultural, a la vez que una expresión de las divisiones de clase y raza.

Las primeras tres décadas de su vida están signadas por su formación como un intelectual de origen colonial: "Los orígenes de mi trabajo y de mis pensamientos han de encontrarse en la literatura europea occidental, en la historia europea occidental y en el pensamiento europeo occidental" (Cudjoe, 1997: 129). En 1917 escribe The Patriotism. Todavia acrítico de la situación colonial, la materia prima de sus primeros escritos provendrán de la vida cotidiana y los personajes que encontrará en la isla. Este acercamiento a la vida del hombre común se entremezcla rápidamente con la agitación de la sociedad trinitense al finalizar la

1. Para una biografia de C.L.R James véase Buhle (1989) o Rosengarten (2008); para un estudio del período formativo de James en Inglaterra, véase Hogsbjerg (2014); una compilación actual acerca de los legados intelectuales de James puede encontrarse en Cudjoe y Cain (1995).

2. Todas las traducciones son propias. 
Primera Guerra Mundial. En 1919 una huelga general visibiliza el ascenso del movimiento anticolonial, con cierta impronta marcada por las protestas de los trabajadores, y con la figura del capitán Arthur Cipriani como su portavoz y líder (en 1929 James escribe su biografia política). En los años 20 la perspectiva vital de James empieza a cambiar y politizarse. En 1925, según su propia autobiografia (no publicada), rompe con la religión. A fines de los 20 se interesa por los textos de Webb Du Bois y Marcus Garvey. En 1931 escribe un artículo contra el racismo en la revista Beacon. Para 1932, cuando parte para Londres (con 31 años), su interés por la política desde joven, su educación religiosa (y las relaciones entre el cristianismo y los ideales de igualdad), junto con su acercamiento a la lectura, la escritura y la crítica, y su conciencia de hombre negro, lo ubican ya en un campo cultural antiimperialista, pero no conoce aún el marxismo.

Invitado por la estrella de cricket de Trinidad Learie Constantine, James se muda en mayo de 1932 para ser el ghostwriter de su autobiografia Cricket and I. En Londres, a instancias de Constantine fue contratado para cubrir los juegos de cricket para el Manchester Guardian y el Glasgow Herald. Pero no todo iba según lo planeado según las Letter from London (1932-1933) su llegada a la capital inglesa lo enfrenta a una serie de hechos de racismo y, especialmente, a la naturalización del racismo en el mundo occidental. Su visión de Occidente cambia, lee La decadencia de Occidente de Oswald Spengler. Pero sin dudas, lo que más lo trastoca, es el ambiente obrero de la ciudad de Nelson, en Lancashire, que lo enfrentará a las realidades del movimiento obrero textil en los tiempos de la gran depresión. La llamada "pequeña Moscú" era una ciudad de 40 mil habitantes en la que residian los Constantine y en la cual James se integra a la vida activa y politica a través del cricket y de su participación en el Nelson Leader con notas sobre el imperialismo y las luchas anticoloniales. Es en Nelson donde se contacta con el Partido Laborista Independiente, la ruptura de izquierda del Labour Party, a través de los militantes del Marxist Group trotskista que actuaban en él. En 1933 un amigo le pasa el primer volumen de la Historia de la Revolución Rusa de León Trotsky que cautiva a James por su prosa narrativa y sus cualidades historiográficas. A partir de allí, James relata que recorrió las discusiones del marxismo con su propia cabeza, leyó a Marx, Lenin, incluso a Stalin y quedó impresionado por sus alevosas deformaciones históricas. En 1934 realiza un viaje a París, en búsqueda de documentos primarios no publicados sobre Toussaint L'Ouverture y la guerra revolucionaria en Haití. Allí ve cómo una huelga general de los trabajadores, emergida desde abajo contra la negativa de socialistas y comunistas para realizar una acción común, derrota la intentona fascista. Según James, este momento sitúa su definitivo pasaje de reformista 
a revolucionario. En 1934 adhiere al trotskismo y cobra protagonismo en el Marxist Group, escribiendo, realizando discursos, trabajando sobre el movimiento obrero y promoviendo las luchas antiimperialistas. Gana especial visibilidad como portavoz de la campaña en contra de la invasión imperialista de Italia en Abisinia en 1935. En 1936 acude a un acto del líder panafricano George Padmore, sin saber que éste era en realidad su amigo de la infancia en Tunapuna que había emigrado a los Estados Unidos y alli se había vuelto vocero de la III Internacional para la cuestión negra. Con Padmore empezará un intercambio político e influirá en la ruptura de éste con el estalinismo y en la elaboración común del International African Service Bureau. Según Padmore, el fundamento de su ruptura con el estalinismo fue que la política de los frentes populares con la burguesía democrática contra los fascismos desconocía el problema de que Francia, Gran Bretaña y otros imperialismos eran las principales potencias colonialistas.

En 1936 James publicará piezas literarias, como una obra de teatro sobre Toussaint L'Ouverture, y Minty Alley sobre la vida de los pobres en Trinidad.

James culmina este período en Inglaterra con la publicación de tres obras que lo muestran como un intelectual público ya en un punto de maduracion: World Revolution: 1917-1936. The rise and Fall of the Communist International (1937), Los jacobinos negros. Toussaint L'Ouverture y la revolución en Haití (1938) y A history of Negro Revolt (1939).

A partir de este momento, la biografia politica e intelectual de James será indisociable de los problemas que la cercana guerra mundial traería a toda una generación de revolucionarios. Desde 1934 hasta 1951 fue un activo militante en las filas de la IV Internacional. En sus años trotskistas tuvo muchos seudónimos: el más conocido, J.R. Johnson. En 1938 llega a Estados Unidos aceptando la invitación de Trotsky y James P. Cannon para liderar el "National Negro Department" del Socialist Workers Party (SWP) con sede en Nueva York. En 1940, participa de la ruptura del SWP y de la formación del Workers Party liderado por Max Shachtman, en el que permanecerá hasta 1948, año en que regresará al SWP, para finalmente formalizar la ruptura con el trotskismo en 1951. Durante esos 15 años James constituirá la base de una tendencia política propia, primero en el trotskismo, y luego ya fuera de él, que oficiará de ambiente de formación de cuadros políticos e intelectuales en Estados Unidos, especialmente en la ciudad de Detroit. Publicará junto a Raya Dunayevskaya y Grace Lee Boggs The Invading Socialist Society como texto programático y de balance de la IV internacional, a la vez que comenzarán la publicación de textos filosóficos del joven Marx y las lecturas de la dialéctica de Hegel de Lenin.

Entre 1949 y 1950 escribe los textos que compondrán American 
Civilization en los que piensa la cultura americana a través de la literatura de Whitman y Melville, el cine, los policiales y la música popular. En 1951 James abre los debates en el SWP "On the woman question: an orientation", que preanuncian una preocupación que desarrollarán colaboradoras cercanas como Selma James o Raya Dunayevskaya. La deportación de los Estados Unidos, en 1953, es la oportunidad para James de escribir Mariners, Renegades, and Castaways: The Story of Herman Melville and the World We Live In, donde plantea cuál es el lugar de la cultura en su comprensión del marxismo.

Durante la década del 50 James desarrolla las tesis sobre las potencialidades revolucionarias de la intervención autónoma de las masas, las que ve confirmadas en la Revolución húngara de 1956. Ese año publica Every Cook Can Govern: A Study of Democracy in Ancient Greece, y junto a Grace Lee y Cornelius Castoriadis el libro Facing Reality (1958), nombre con el que sus seguidores americanos pasan a llamar a su organización hasta 1970.

Hacia fines de los 50, James es invitado por el presidente Kwame Nkrumah a visitar a la Ghana independiente. En 1958 regresa a Trinidad y durante la década de 1960 apoyará los movimientos radicales del Caribe (Jamaica, Cuba, Guyana y Haití), con la idea de que una liberación de las West Indians de conjunto abriria una perspectiva al socialismo. Coincide así con el fortalecimiento de un movimiento panafricano más general como el de los movimientos de liberación de los pueblos africanos y la emancipación de los negros en los Estados Unidos. En este período James privilegia el apoyo a los liderazgos negros de masas, como el de Nkrumah o el de Eric Williams, que logran avanzar en la descolonización con políticas nacional-populares, pero se ve obligado a romper con ambos, ya que su dinámica no fue la de una revolución radical y anticapitalista.

En 1963 publicará Beyond a Boundary, una historia social del deporte plena de rasgos autobiográficos, en la cual James reconstruye el lugar del cricket para los jóvenes negros de Trinidad. El libro es el punto más alto de las preocupaciones culturales de James.

En las siguientes décadas James publicará numerosos artículos, escribirá innumerables cartas, dictará conferencias, prologará y reseñará libros abordando los problemas de la cultura, el marxismo, la descolonización en África, las luchas contra el estalinismo, la literatura caribeña, entre otras cuestiones. Muchos de ellos se compilarán en diversos libros, entre los que podemos mencionar Marxism and the intellectuals (1962), Nkrumah and the Ghana Revolution (1977), The future in the present (1977), Spheres of existence (1980). También publicará, sobre estética y literatura, Sobers (1969), Picasso and Jackson Pollock (1980) y Three Black Women Writers (1981). Por esos años se abocará 
también a escribir su no publicada autobiografia. En la década de 1980 una serie de entrevistas con E.P. Thompson, Stuart Hall, Paul Buhle y Tariq Ali, permiten una mayor visibilidad de James. En ellas expone retrospectivamente su biografia política, las contribuciones de su obra y opina sobre la politica mundial. Allí defiende su apoyo a las revoluciones cubana y china, y se detiene en un balance de las revoluciones en lo que va del siglo reparando en las perspectivas de las luchas en Polonia contra el estalinismo y su colaboración con el movimiento Solidaridad de Walesa. Muere en 1989. En los 90 comienzan a aparecer las publicaciones sobre su obra y las primeras biografias en Estados Unidos y otros países anglófonos. Como si la coincidencia del año de su muerte y la caída del muro de Berlín otorgaran al autor de "Ascenso y caída de la Internacional Comunista" un nuevo interés público.

\section{Los jacobinos negros}

Los jacobinos negros es, al igual que su autor, una combinación entre lo extraordinario y un producto de su época. Extraordinario porque es el primer libro que presenta una reconstrucción historiográfica y una comprensión sociopolítica de la gran "revolución olvidada": ${ }^{3}$ la única revolución de esclavos triunfante que, en el transcurso de su rebelión, derrotaron a los blancos de Santo Domingo, a los soldados de la monarquía francesa, a los ingleses y españoles que aprovecharon el río revuelto, y al ejército de Napoleón Bonaparte. Revolución que transformó a Santo Domingo en Haití, la primera colonia descolonizada de "nuestra América" y la única que fundó un Estado negro. Producto de su época, porque el libro, escrito en Londres en la década del 30, condensa las elaboraciones y debates de la tradición del marxismo clásico que tenía en Inglaterra un epicentro intelectual y político de envergadura. Más aún, saliendo de una mirada eurocéntrica, condensa también lo que hoy se reconoce claramente como una generación de intelectuales caribeños que tuvo en Trinidad y Tobago un punto neurálgico (Cudjoe, 1997).

3. Samir Amín, en su introducción al libro de Frantz Fanon Piel negra, máscaras blancas, define del siguiente modo a la revolución haitiana: "La primera y única revolución social que conoció el continente americano, hasta tiempos muy recientes, fue la de los esclavos de Santo Domingo (Haitî), que conquistaron su libertad por sí mismos. La pretendida "Revolución americana" del siglo XVIII, como las posteriores de las colonias españolas, no fueron sino revueltas de las clases dominantes locales que buscaban librarse de los tributos que pagaban a la madre patria para continuar con la misma explotación de los esclavos y de los pueblos conquistados que emprendieron las metrópolis del capitalismo mercantilista. Nunca tuvieron una revolución en el sentido completo del término" (2009: 6). Acerca de la revolución haitiana, véase el trabajo de Eduardo Grüner (2010). 
Desde el punto de vista historiográfico, Los jacobinos negros tiene su antecedente directo en Historia de la Revolución Rusa de León Trotsky. Esto puede rastrearse en varios planos. El primero, la forma en que James analiza la revolución en Santo Domingo a la luz de la dinámica de la "revolución permanente" como movimiento de transcrecimiento de demandas, y del desplazamiento de clases y alianzas de clases que ese transcrecimiento produce. El proceso haitiano es leído en clave del despliegue de contradicciones que una revolución burguesa dispara, en una colonia basada en el trabajo esclavo, entre los "grandes blancos" -propietarios de plantaciones, aristocracia francesa, clero y agentes de la burguesía marítima-; los "pequeños blancos" -profesiones liberales, burocracia estatal, comerciantes minoristas y artesanos-, y los mulatos y los negros -trabajadores que detentaban más o menos libertad y que no constituían un colectivo homogéneo-. Esa dinámica, cuyo punto de partida es la abolición de la esclavitud que proclamaron los franceses para hacer frente a la guerra con Inglaterra, configura una revolución que, en palabras de James, "las masas de Santo Domingo comienzan" y "las masas de París la completan". Los "jacobinos negros" son el producto de esa especial combinación. El segundo plano que lo vincula a Trotsky es el modo en que se combinan los determinantes históricos (económicos, geográficos, geopolíticos y de la lucha de clases a nivel mundial) con el papel del "hombre en la historia". Esa tensión tan discutida en las ciencias sociales es transitada por James con naturalidad. La figura de Toussaint L'Ouverture, ex esclavo devenido negro libre, es equiparada por el propio James a los personajes de la tragedia transformándolo, en forma expresa, en un héroe trágico que condensa la historia de toda una época. Profundamente admirado por el autor y tratado con cierta clemencia respecto de sus "errores políticos", es explicado, sin embargo, por condiciones que aprovecha, que moldea, que lleva hasta su limite, pero que no puede inventar:

La revolución de Santo Domingo será en gran medida una glosa de sus éxitos y de su personalidad política. El autor cree y confia en que esta narración demostrará que entre 1789 y 1815 , con la única excepción del propio Bonaparte, la historia no registra la irrupción de ninguna figura individual más carismática que la de este negro, esclavo hasta la edad de 45 años. Sin embargo, Toussaint no fue quien hizo la revolución. Fue la revolución quien hizo a Toussaint [...] Las grandes personalidades hacen la historia, pero solo la historia que les es dado hacer. Su libertad de acción está limitada por las necesidades de su entorno. Reflejar los límites de tales necesidades y la realización, completa o parcial, de todas las posibilidades: tal es el auténtico desafio del historiador" (2003: 18). 
Definición concisa de la tarea historiográfica: escrutar y desgranar los límites del momento histórico, y a la vez preguntarse y rastrear las potencialidades que están inscriptas en él, el nivel en que éstas se desplegaron y los sujetos que posibilitaron ese despliegue. El tercero es el carácter "cinematográfico" del libro. Al igual que en Historia de la Revolución Rusa, el lector se sumerge en una narración que, sin perder las coordenadas de los grandes acontecimientos, tiene algo de intima, de personal, que vuelve imposible esquivar la tensión y el apasionamiento. Esto no es producto de una estética en sentido superficial, o de un estilo. Es la combinación entre sus dotes literarias (recordemos que James quería, antes que nada, ser escritor y era un ávido lector de literatura) y su compromiso político, su punto de vista "from below".

Esta estructura narrativa no está puesta, únicamente, al servicio de relatar el proceso de esa revolución inesperada. Está puesta también al servicio de desarrollar una tesis fundamental del libro que luego será desarrollada en A history of negro revolt un año después: la tesis sobre el protagonismo de los esclavos negros en la constitución de las sociedades capitalistas. Los negros son corridos, en la visión de James, del lugar de mera víctima para ser colocados en el lugar de factor fundamental, de condición necesaria en el desarrollo del capitalismo. Superando los esquemas liberales que oponían (de modo excluyente) formas sociales precapitalistas o arcaicas a formas capitalistas o modernas, James, haciendo uso creativo de la ley de desarrollo desigual y combinado, entiende y explica la esclavitud como un modo enteramente capitalista de obtener y someter fuerza de trabajo, aunque este modo remitiera y aprovechara formas sociales previas. Sostener eso hoy no presenta gran novedad porque hay pluralidad de estudios que han analizado el papel de los procesos de esclavización en el desarrollo del capitalismo. Decirlo en 1938, siendo negro y nativo de Trinidad, y como parte de una de las primeras comprensiones marxistas de las revoluciones fuera de Europa, significó en sí mismo un hito en la historiografia marxista. Como señaló James Walvin (2003), Los jacobinos negros es uno de los "manifiestos historiográficos antiimperialistas en la antesala de la decolonización". Este carácter pionero es, sin embargo, más comprensible si, como veremos en el próximo apartado, la obra de James se sitúa en el marco de los debates al interior del marxismo revolucionario, particularmente de la corriente trotskista en la cual, empezando por el propio Trotsky, la "cuestión negra" constituía un eje de discusión.

Pero este carácter necesario de los esclavos negros en el desarrollo del capitalismo no se da, únicamente, de la mano de su papel en "la acumulación originaria" en las colonias. Se da también en el plano político. Si la revolución de Haití no puede comprenderse sino como parte del impulso de la Revolución Francesa, sus consecuencias no pueden 
encorsetarse en esa isla del Caribe: los esclavos negros que, con su revolución, consiguen su libertad pero también la independencia nacional, pasan a ser parte, por obra de su propia lucha, de la historia de las revoluciones burguesas (y de sus peligros para la propia burguesía). Los esclavos negros se transforman por primera vez, en la obra de James, en sujeto protagónico, social, económico y politico, de las sociedades modernas de occidente. E incorporan, a la dinámica comparable a la de la Gran Revolución, un factor inexistente en aquélla y que, desde el inicio, desplaza y reconfigura las fracciones y alianzas de clase: la raza. La definición de los revolucionarios como el colectivo de los "trabajadores negros" es la muestra más sintética de esta imbricación:

Toussaint, anteriormente esclavo, con su ejército de ex esclavos dirigidos por ex esclavos, la más poderosa fuerza de Santo Domingo, era esencialmente el hombre de los trabajadores negros [...] No era una cuestión de color sino una cuestión de clases en su más cruda expresión, pues los negros que anteriormente habian sido libres seguian siendo fieles a los mulatos. Personas de cierta alcurnia y relevancia bajo el Antiguo Régimen seguían viendo a los ex esclavos como personas que, esencialmente habian nacido para ser gobernadas (2003: 161).

La revolución haitiana es explicada por James en el cruce entre la historia de la imbricación de Santo Domingo en los procesos desplegados por la promesa de igualdad de la república burguesa y la historia de la segregación racial y resistencia de los negros a la esclavitud. La combinación de estas dos "promesas" (libertad e igualdad) es la que marca el ritmo de la revolución, y de la adopción por parte de las clases explotadas (los esclavos) de un programa antes siquiera soñado: la ciudadanía y, como su consecuencia, el derecho a elegir el propio gobierno (lo que, llevado hasta el final, deriva en la declaración de la independencia de Haití). Pero la combinación de estas dos promesas es la que marca también las contradicciones de la propia figura de L'Ouverture quien, abrazando los principios de la República y su extensión para los negros, defiende hasta último momento el dominio de Francia sobre la isla, oponiéndose a la independencia de la dominación colonial. Esa defensa hace que cometa el que James considera su único "error": condenar el nacionalismo negro de Moisé y confiar en Napoleón -aunque ya hubiera expresado su intención de volver a instaurar la esclavitud en la isla-, para viajar a Francia, donde fue apresado hasta su muerte.

Al relato de este proceso que es, en sí mismo, apasionante, James le agrega una pluma que vuelve a Los jacobinos negros una singular "mezcla de ciencia y arte". 


\section{El marxismo y la cuestión negra}

Al igual que con Los jacobinos negros, las elaboraciones que James realiza sobre la cuestión negra son indisociables de su adhesión al marxismo revolucionario a mediados de la década del $30 \mathrm{y}$, particularmente, de su experiencia vital en Estados Unidos desde 1939 hasta 1951. ${ }^{4}$ Pero son incomprensibles, también, sin elementos que anteceden a esta década, y son parte de la formación de James en sus años de juventud. ${ }^{5}$ Cuando tenía alrededor de 20 , junto con su amigo de la infancia Malcolm Nurse (quien adoptaría luego el pseudónimo de George Padmore), se hizo lector del semanario Negro World, periódico publicado por United Negro Improvement Association bajo la dirección de Marcus Garvey. Pese a la simpatía que le despertaba el predicador y líder de un movimiento multitudinario, nunca acordó con la política de "Back to Africa" que impulsaba la "repatriación" de los negros del Caribe y de Norteamérica a su viejo continente. Más tarde, James lo recordaría como "la persona que hizo que se diera cuenta que ser Negro era algo políticamente importante" (Rosengarten, 2008: 20). En 1931, la revista Beacon publica un artículo titulado "Race Admixture" en el que el autor, fundamentando sus argumentos en novedosos tests de inteligencia realizados en Estados Unidos, afirmaba el origen biológico de la inferioridad de los negros. Ese artículo dio la oportunidad a James de hacer su aparición pública a través de una respuesta en la que argumentaba en defensa de la igualdad de negros y blancos y rescataba la figura de Toussaint L'Ouverture como líder de la revolución en Haití (muestra de que sus estudios sobre ese proceso ya habian comenzado en Trinidad).

Como dijimos más arriba, el viaje a Inglaterra en 1932 es un primer punto de inflexión no sólo porque es allí donde toma contacto con el marxismo clásico y, particularmente, con la oposición de izquierda al

4. Los textos sobre la cuestión negra incluyen artículos de periódicos, panfletos o documentos partidarios que James escribe (la gran mayoría bajo seudónimos militantes) entre 1939 y 1950, es decir, durante su estadía en Estados Unidos. Véase McLemee (1996).

5. El problema del "autogobierno" tenía una historia reciente en Trinidad. En 1887, comienza un ascenso de movilizaciones por la reforma constitucional en la isla y el denominado Movimiento Reformista, dirigido por miembros de las clases medias triniteñas, alcanza su esplendor. Ese año, James Anthony Froude, profesor de Oxford, visitó Trinidad y escribio "The English in the West Indies", un artículo dedicado a argumentar por qué los nativos de Trinidad no podian ejercer su propio gobierno. Eso desató una serie de respuestas de intelectuales negros de la isla, entre los que estaba John Jacob Thomas, quien escribirá "Froudacity: West Indian Fables by James Anthony Froude". Todo el debate y, en particular, el escrito de Thomas, va a influir en la formación de James. Véase Cudjoe (1997). 
estalinismo, sino también por el impacto que tuvo la vivencia del racismo en su subjetividad.

Dos serán las principales preocupaciones que estarán presentes desde alli hasta la elaboración de "The revolutionary answer to the Negro Problem in the United States" (1948), texto que James considera su escrito más acabado sobre el problema: el tratamiento de la relación entre la opresión de clase y la de raza, y, directamente relacionado con esto, el programa que debian levantar los socialistas revolucionarios hacia los movimientos de lucha de las comunidades afroamericanas, particularmente en Estados Unidos. Podría decirse que la definición de la dialéctica entre clase y raza James ya la había establecido en Los jacobinos negros cuando señala:

En política la cuestión racial es subalterna a la cuestión de clase, y pensar el imperialismo en términos raciales es catastrófico. Pero subestimar el factor racial entendiéndolo como algo meramente incidental no es un error menos grave que considerarlo algo fundamental (2003: 263).

El álgebra concreta que irá tomando esta definición general será el contenido de largos e intensos debates durante 15 años, debates que se desarrollarán al interior del movimiento trotskista, en confrontación con las políticas de la Internacional Comunista (IC) y en diálogo con los posicionamientos del movimiento panafricano.

1939 es el segundo punto de inflexión y un año determinante: James se muda a Estados Unidos y allí descubre un doble proceso que lo obliga a colocar en el centro de sus reflexiones y de su militancia la "cuestión negra". Por una parte, se encuentra con un clima social en el que la comunidad negra norteamericana presentaba rasgos de mucha actividad e incluso de un giro a la izquierda que abría, según James, grandes posibilidades de construcción para los trotskistas. Por otra, se encuentra con un partido (el SWP) cuya dirección tiene muy pocas elaboraciones al respecto y muy poca tensión puesta en la inserción en dicho movimiento negro. Esto hace que James se meta, de lleno, en el centro de un debate entre el marxismo ruso y el norteamericano que ya llevaba diez años. En 1928 Trotsky habia insistido en que los negros constituian el sector más desposeído del proletariado norteamericano, motivo por el cual la cuestión negra se volvía parte fundante del modo de concebir la construcción del movimiento revolucionario en Estados Unidos. En 1929 la IC había impulsado una caracterización de los estados del sur de Estados Unidos como un "black belt" y consideraba que, en el transcurso de un ascenso revolucionario, era necesario impulsar la conformación de un estado negro independiente. Esa política se ba- 
saba, en los argumentos de la propia IC, en las elaboraciones de Lenin sobre la "cuestión nacional" y la postulación de la independencia de las naciones oprimidas como programa de los revolucionarios.

Esto abre un gran debate al interior del trotskismo sobre la independencia (o no) de la organización del movimiento negro respecto de las organizaciones de la clase obrera blanca (por ejemplo, los sindicatos), y sobre la subsunción (o no) de las demandas de los negros a las demandas de la clase obrera en su conjunto (que eran, en los hechos, las demandas de la clase obrera blanca). Contra los trotskistas norteamericanos que se oponían radicalmente a la política de la IC y postulaban la igualdad social, económica y política de los negros como programa general, Trotsky advertía que, sin adherir a la caracterización del "black belt", existía la posibilidad de que, en su lucha contra la opresión blanca, los afroamericanos pudieran emerger como una minoría nacional. En última instancia, su posición era que los trotskistas no podian subordinar la liberación de los negros a la emancipación de la clase obrera en general (clase obrera que, por otra parte, era profundamente racista); sino más bien estar atentos a la dinámica que la lucha de los afroamericanos adoptara y estar abiertos a su autodeterminación como minoría nacional si así lo exigieran. A eso agregaba:

Es posible, entonces, que los negros se conviertan en la sección más avanzada. Ya tenemos un ejemplo similar en Rusia. Los rusos eran los negros de Europa. Es muy posible que también los negros, a través de la autodeterminación, procedan a la dictadura del proletariado dando un par de pasos gigantescos por delante del gran bloque de trabajadores blancos. Ellos se transformarán entonces en la vanguardia. Estoy absolutamente seguro de que, en cualquier caso, lucharán mejor que los trabajadores blancos. (Trotsky, 1933)

Pese a este posicionamiento de Trotsky, los trotskistas norteamericanos nunca compartieron la importancia de la cuestión negra en la construcción del movimiento revolucionario. De modo que, cuando C.L.R. James llega a Estados Unidos, la situación era débil, no sólo teórica y programáticamente, sino también en cuanto a la inserción política en el movimiento afroamericano. Eso impulsa a James a escribir un documento que sintetiza esa crítica al tiempo que propone revertir la situación. Nacen así las "Notas preliminares sobre la cuestión negra", escrito que será el borrador de una serie de debates que James tendrá dentro del SWP y que lo llevará a encontrarse con Trotsky en México en abril de 1939. Si bien James desecha la discusión de los negros como minoría nacional y el programa de la autodeterminación, sí propone 
firmemente que los trotskistas levanten la política de construcción de organizaciones independientes de los afroamericanos (aunque éstas no fueran socialistas). En su argumentación tomaba como ejemplo el crecimiento que había tenido la organización de Marcus Garvey luego de la Primera Guerra Mundial, para mostrar el potencial revolucionario que podian tener organizaciones independientes y militantes de los afroamericanos. Si bien volvía sobre lo errado del programa de "Back to Africa", remarcaba el espacio político que había encontrado un programa radical en la comunidad negra.

Cuando vuelve de su encuentro con Trotsky en México, James decide ir por tierra pasando por New Orleans para ver "las cosas con sus propios ojos" (nunca habia estado en el sur antes). Alli es que, por primera vez, toma contacto con el nivel de opresión de los negros en el sur y con las expresiones de brutal racismo en la sociedad sureña.

A su llegada a Nueva York, James prepara los documentos para la convención nacional de SWP. Presenta dos mociones, ambas aceptadas. La primera, si bien no hace mención a un estado negro separado, está directamente relacionada con las discusiones con Trotsky: postula que el partido debe afirmar expresamente el derecho de los afroamericanos a la autodeterminación nacional, si eso eligieran, en el curso del proceso revolucionario. La segunda, la formación del Departamento Negro a nivel nacional que tenía como responsabilidad desarrollar actividades teóricas y políticas que le dieran el peso necesario a la cuestión negra dentro del partido. James es, obviamente, designado director del departamento.

El triunfo de la política de James sobre la cuestión negra al interior del SWP se vio empañado con el advenimiento de la guerra y la ruptura interna que generaron los posicionamientos sobre la URSS. James abandona el partido. Siete años después, el grupo que él dirige decide volver al SWP. Es interesante porque este retorno tiene estricta relación con la cuestión negra y su centralidad para pensar la clase obrera norteamericana. El SWP había sido el único grupo que había intervenido (y en algunos casos en forma protagónica) en las luchas y también en la producción de materiales sobre el tema. Por ejemplo, en 1942, el SWP juega un rol protagónico en la defensa de Odell Waller, un aparcero negro de Virginia que fue condenado a linchamiento legal por haber actuado en defensa propia contra el dueño de las tierras en las que trabajaba. Además, el SWP se había triplicado en tamaño desde 1940, crecimiento que también había aumentado la participación negra en el grupo.

Luego de la fusión, el SWP le pide a James que escriba el documento sobre la cuestión negra para la convención nacional del partido en julio de 1948. Escribió "Negro Liberation Through Revolutionary Socialism", que fue aceptado por la convención. Ese documento era una versión 
corregida y abreviada de "Historical Development of the Negroes in American Society" escrito en 1943. En la presentación del documento, James hace una alocución que resume los años de actividad política y estudio sobre la politica afroamericana en Estados Unidos. "The revolutionary Answer to the Negro Problem in the United States" (1948) es la culminación de esa acumulación teórica y práctica.

Sin embargo, a pesar de esta confluencia por la que el SWP aceptaba las tesis de James sobre la cuestión negra, James culminaria su ruptura con el trotskismo como corriente y llegaria a una nueva noción sobre las luchas de la clase trabajadora alternativa al modelo leninista de partido.

\section{De World Revolution a las Notes sobre la dialéctica}

Si hay un rasgo permanente en el marxismo de James es la búsqueda de una política socialista antiestalinista. En su original trayectoria dentro del movimiento trotskista, él desarrolló los núcleos principales de un marxismo iconoclasta marcado por tres elementos: una nueva teoría acerca de la URSS, la búsqueda de un enriquecimiento del método marxista y finalmente una nueva consideración de la relación entre la clase y el partido.

En 1937 James publica World Revolution 1917-1936: The Rise and Fall of the Communist International (James, 2017). El libro era el producto de la maduración de la filiación de James con las ideas de León Trotsky y de su rol en el trotskismo inglés. El objetivo era ofrecer al público inglés una historia de la Internacional Comunista alternativa a los panegíricos estalinistas que inundaban el mercado editorial. Dentro de los estudios sobre la trayectoria intelectual de James se suele considerar que el punto de vista "trotskista" de la obra haria de World Revolution su libro menos original. Según esta lectura, allí se repetirian los argumentos de Trotsky contra la política de la IC bajo Stalin, y este último aparecería como el "deus ex machina" de las derrotas de la revolución en China, Alemania y España. Sin embargo, como señala Al Richardson (1993) en el prólogo a una nueva edición, ni James ni Trotsky tenían esa visión tan servicial. ${ }^{6}$ La perspectiva de James tenía importantes matices (tanto teóricos, como tácticos), de los que él y Trotsky eran conscientes. El tono del libro difería en algunos puntos del sostenido por el movimiento de la IV Internacional, diferencias que pueden atribuirse a que James se hacía eco de algunas posiciones de grupos ultraizquierdistas, como el grupo Que Faire francés o de Boris Souvarine, al que James le traducirá al inglés su biografia de Stalin en 1938. La discrepancia sustancial de estos grupos con el trotskismo 
residía en que consideraban que la degeneración de la Rusia soviética había comenzado y se había completado mucho antes de lo que Trotsky estaba dispuesto a admitir. Por otro lado, James también conocía la teoría del grupo francés dirigido por Henri Chaze que sostenía que la URSS podía constituir algún tipo de "capitalismo de estado". A pesar de estos matices, ya presentes en este periodo (y que se profundizarán luego), World Revolution culmina señalando que la IV internacional es la única perspectiva para el movimiento obrero mundial.

En 1938 James participa de la conferencia de fundación de la IV Internacional. La discusión acerca del estalinismo no deja de aparecer en las postrimerias de la II Guerra Mundial. Luego del pacto germanosoviético emergerá un debate de proporciones en la IV internacional, especialmente en la sección norteamericana del SWP, en donde Max Schachtman y James Burnham proponen abandonar el "defensismo" y postular algún tipo de "derrotismo revolucionario". ${ }^{7}$ James es solidario de esta posición, aunque difiere con ellos en la caracterización de la URSS. Como queda patente en los debates de En defensa del marxismo, ${ }^{8}$ esta alternativa politica resultaba sumamente abstracta para Trotsky (1975). Para él la restauración del capitalismo no se había consumado en la medida en que la propiedad nacionalizada y el monopolio del comercio exterior ponian trabas a la libre acumulación capitalista y hacian de la sociedad rusa una economía de transición inestable frente a los vaivenes de la situación mundial. Más allá de las cuestiones teóricas, Trotsky exigía a los críticos un programa común descartando de plano la posibilidad de no defender la URSS ante una probable invasión nazi. Será ese punto el que cruce Schachtman que se separa del SWP para fundar el Workers Party. James participará en el WP, pero empezará a desarrollar su propia posición junto a Raya Dunayevskaya y Grace Lee Boggs ya a partir de $1941 .^{9}$ En 1945 fundarán la Johnson-Forest Tendency (tomando el nombre de sus seudónimos). Su punto de vista es que la URSS era un "capitalismo de estado", mientras que la mayoría adherirá a la teoría del colectivismo burocrático. ${ }^{10}$

Algunos libros de este período de ruptura son medulares para entender del marxismo de James. Uno de ellos es Notes on Dialectics que es el resultado de una serie de cartas y reflexiones escritas por James en el año 1948 desde la ciudad de Nevada a los miembros de la J-F

7. Sobre las discusiones del trotskismo en la II Guerra Mundial, ver Liszt (2004).

8. Conjunto de artículos escritos entre 1939 y 1940, publicados como libro por primera vez en 1942 por el Socialist Workers Party de Estados Unidos.

9. Sobre el período que va de 1939 a 1949, véase la compilación de textos realizada por McLemee y LeBlanc (1994).

10. Sobre las polémicas de Trotsky con estás teorias, ver Cinatti (2005). 
Tendency que residian en Nueva York y Detroit. El texto fue conocido desde entonces como el "Nevada Document". ${ }^{11}$ Posteriormente, James consideró que esa obra constituye su contribución más importante al marxismo. El objetivo del escrito es exponer las conclusiones de un trabajo teórico llevado adelante junto a Dunayevskaya y Boggs, con quienes se había abocado a la importante tarea de traducción de textos de Marx y de Lenin. La primera tradujo del ruso diversos textos, entre ellos los Cuadernos filosóficos de Lenin que tendrá terminados en 1949, aunque los publicará recién en 1957 por ausencia de interés de las editoriales americanas; y Boggs, doctorada en filosofia, realizará la traducción del alemán de tres de los Manuscritos de 1844 de Marx. La lectura de Hegel que tiene el grupo mantiene una deuda importante con Herbert Marcuse y su libro Razón y revolución publicado en 1941. Más allá de esto, el trabajo del grupo intenta realizar aportes novedosos, entre ellos la incorporación de los debates sobre Lenin y la dialéctica, y la búsqueda de una aplicación de los debates filosóficos a las luchas políticas, que provenía sin dudas de las polémicas sobre la URSS que habian enfrentado a Trotsky con los antidefensistas.

Desde el punto de vista estricto de la filosofia de Hegel, el libro ofrece una descripción de los conceptos de Ciencia de la lógica y expone la relación de éstos con la filosofia de Marx. La mayor originalidad teórica es que propone como objeto de "cognición filosófica" la historia del movimiento obrero. Según James su propósito era "transferir" el método dialéctico a la historia social y política, para explicar mediante las nociones filosóficas hegelianas los momentos principales del curso histórico del movimiento obrero. El intento de comprender los estadios de la organización obrera como estadios de la conciencia de las masas, aprehendidos en un movimiento totalizador, tiene el interés, según el propio James, de ofrecer un nuevo comienzo para el marxismo que recalque la autoactividad de la clase trabajadora. Así, por ejemplo, James se interroga si las masas obreras estaban equivocadas al seguir al estalinismo, que según Trotsky era una aberración de la historia, o si éste tenía un lugar objetivo en el propio desarrollo del movimiento obrero, y si no se correspondia con el desarrollo de una etapa del capitalismo. El argumento de la URSS como "capitalismo de estado", ya presente desde inicios del 40, encontraba ahora su explicación a partir de considerarlo como estadio más general del capitalismo en su conjunto, determinando el lugar del estalinismo.

En State capitalism, de 1950, James sostiene que la burocracia es la personificación directa del capital en la URSS y criticará a Trotsky por 
identificar la estatización de los medios de producción con el Estado obrero o de transición al socialismo. Para James lo correcto es la afirmación exactamente contraria por la cual la tendencia a la estatización de los medios de producción es un desarrollo endógeno del capitalismo, ${ }^{12}$ una tendencia histórica vigente no solo en la URSS sino a escala global dando cuenta del cambio en el modo de producción (Van der Linden, 2007).

Esto trastocaría también el lugar de las organizaciones del movimiento obrero. En Notes James señala que el carácter masivo de la identificación entre el partido y la clase obrera que se daba en los partidos comunistas de la posguerra, específicamente el italiano que agrupaba dos millones y medio de miembros, volvian caduca la tarea de organizar partidos de la clase obrera en tanto fracciones de ésta. Si la revolución avanzaba, se organizarian entre 6 y 7 millones de trabajadores, lo cual no era un partido sino que era la clase misma. De ahí que para James la tarea de la hora era abolir la organización partidaria y dar rienda suelta al elemento espontáneo de la clase obrera. Aunque la fuente primordial de este razonamiento era un Lenin hegelianizado, la consumación del argumento también llevaría a la crítica del leninismo porque, precisamente, el fundamento de la teoría de Lenin sobre la organización era la ausencia de una continuidad orgánica entre clase y partido, y la necesidad de organizar a los sectores avanzados de la clase. James consideraba esta cuestión ya superada por la dialéctica de la historia, motivo por el cual el objetivo del movimiento marxista debía ser promover la actividad desde abajo del movimiento obrero con independencia de cualquier mediación política. Así, en 1951 James rompe con las premisas del trotskismo.

Esta dialéctica de las masas, sin mediaciones, era un argumento que familiarizará a James con Lefort y Castoriadis que en Francia también romperán con la IV internacional en 1948 y animarán el grupo Socialismo o Barbarie. En Facing reality, coescrito con Grace Lee Boggs y Castoriadis, los acontecimientos de la Revolución Húngara de 1956 confirmarian esta nueva perspectiva. A partir de este momento James sostendrá que una nueva sociedad emergente anida y se desarrolla desde las entrañas de la vieja sociedad, abonando uno de los tópicos de la nueva izquierda posterior a 1968.

\section{Palabras finales}

Más allá de la ilusión política que esta nueva noción de emancipación implicaba, el interés de James por la actividad de las masas y el desa-

12. https://www.marxists.org/archive/james-clr/works/1947/balance-sheet/ch04. htm. 
rrollo de la personalidad de los oprimidos encontrará asilo en relevantes obras sobre el lugar de la cultura en el capitalismo. En los escritos sobre la vida cotidiana y los gustos culturales presentes en el movimiento obrero del mundo de posguerra, anticipatorias de las preocupaciones de la nueva izquierda de los 60, James intentó anudar el análisis de los cambios en la vida obrera, con la cuestión negra y la lucha contra la opresión de la mujer. Esto lo sitúa como una referencia intelectual y política en una diversidad de campos de la cultura de izquierda, que impactó en historiadores como E. P. Thompson, pioneros de los estudios culturales como Stuart Hall, investigadores del trotskismo como Al Richardson o referentes del poscolonialismo como Edward Said. James se configuró así como el autor de una obra que va más allá de las fronteras disciplinares, pero también geográficas, y que transformó a un antillano descendiente de esclavos africanos en un intelectual cuyo legado es objeto de diversas apropiaciones, construyendo los muchos James de los que hablamos al inicio. Esa heterogeneidad, que es sin duda una de sus mayores riquezas, no niega un hilo sin el cual es imposible retejer la historia de este singular marxista: su compromiso y dedicación durante la totalidad de su vida a la búsqueda de los caminos de la emancipación social y el socialismo. Es allí donde se fragua su inseparable relación con el marxismo. Parte de los jóvenes que sintieron el golpe de la Revolución Rusa como acontecimiento vital que marcó a toda una generación de intelectuales y militantes, James encontró en el marxismo el universo para desplegar su creatividad, la delicadeza de su sensibilidad y la inquietud de su inteligencia. A cien años de esos días que conmovieron al mundo, la recuperación de su figura es también una invitación a sumergirse en las pasiones, intelectuales y políticas, que esa revolución despertó.

\section{Referencias bibliográficas}

Amin, Samir (2009), "Introducción: Frantz Fanon en África y Asia", en Frantz Fanon, Piel negra, máscaras blancas, Madrid: Akal.

Anderson, Kevin (1995), Lenin, Hegel and Western Marxism: a critical study, University Illinois Press.

Buhle, Paul (1989), CLR James: The Artist as Revolutionary, Londres-Nueva York: Verso.

Cinatti, Claudia (2005), "Del stalinismo a la restauración capitalista en la ex URSS", Estrategia Internacional, $\mathrm{n}^{\circ}$ 22, Buenos Aires.

Cudjoe, Seldwyn (1997), "C.L.R. James y la tradición intelectual de Trinidad y Tobago. O no se estudia Shakespeare debajo de un árbol de mango", en New Left Review, n ${ }^{\circ}$ 223, mayo-junio (versión español). 
- y William E. Cain (eds.) (1995), CLR James: His intellectual legacies, University of Massachusetts Press.

Grüner, Eduardo (2010), La oscuridad y las luces. Capitalismo, cultura y revolución, Buenos Aires: Edhasa.

Hogsbjerg, Christian (2014), CLR James in Imperial Britain, Durham: Duke University Press.

James, C.L.R. (1980), "Discovering Literature in Trinidad: The NineteenThirties", Spheres of Existence, Londres: Allison and Busby.

- (2003), Los jacobinos negros, Madrid: Fondo de Cultura Económica-Turner.

- (2017), World Revolution 1917-1936: The Rise and Fall of the Communist International, Durham: Duke University Press.

Liszt, Gabriela (2004), "Ensayo introductorio", en León Trotsky, Guerra y revolución, Buenos Aires: Ceip.

McClendon, John H. III (2005), C.L.R. James's Notes on Dialectics. Left Hegelianism or Marxism-Leninism?, Lanham: Lexington Books.

McLemee, Scott (1996), C.L.R. James on the "Negro Question", University Press of Mississipi.

- y P. LeBlanc (1994), C.L.R. James and Revolutionary Marxism: Selected Writings of C.L.R. James, 1939-1949, Nueva Jersey: Humanities Press.

Richardson, Al (1993), "Introduction", en World Revolution 1917-1936. The Rise and Fall of the Communist International, Londres: Humanities Press.

Rosengarten, Frank (2008), Urbane Revolutionary. CLR James and the Struggle for a New Society, University Press of Mississippi.

Said, Edward (1989), "Review C.L.R. James: The Artist as Revolutionary", en New Left Review, ${ }^{\circ} 175$, Londres.

Trotsky, León (1933), "The Negro Question in America" en https://www. marxists.org/archive/trotsky/works/1940/negro1.htm\#prinkipo.

- (1975), En defensa del marxismo, Buenos Aires: Yunque.

Van der Linden, Marcel (2007), Western Marxism and the Soviet Union. A survey of Critical Theories and Debates since 1917, Boston: Brill.

Walvin, James (2003), "Introducción” a Los jacobinos negros, Madrid: Fondo de Cultura Económica-Turner 